University of Louisville

ThinkIR: The University of Louisville's Institutional Repository

\title{
The patient's view of orthodontic training requirements and the influence of board certification or a master's degree on their choice for an orthodontist.
}

Justin Trisler 1980-

University of Louisville

Follow this and additional works at: https://ir.library.louisville.edu/etd

\section{Recommended Citation}

Trisler, Justin 1980-, "The patient's view of orthodontic training requirements and the influence of board certification or a master's degree on their choice for an orthodontist." (2012). Electronic Theses and Dissertations. Paper 1458.

https://doi.org/10.18297/etd/1458

This Master's Thesis is brought to you for free and open access by ThinkIR: The University of Louisville's Institutional Repository. It has been accepted for inclusion in Electronic Theses and Dissertations by an authorized administrator of ThinkIR: The University of Louisville's Institutional Repository. This title appears here courtesy of the author, who has retained all other copyrights. For more information, please contact thinkir@louisville.edu. 


\title{
THE PATIENT'S VIEW OF ORTHODONTIC TRAINING REQUIREMENTS AND THE INFLUENCE OF BOARD CERTIFICATION OR A MASTER'S DEGREE ON THEIR CHOICE FOR AN ORTHODONTIST
}

\author{
By Justin Trisler \\ BSc Berry College, 2002 \\ DMD University of Alabama Birmingham School of Dentistry, 2006
}

\author{
A Thesis \\ Submitted to the Faculty of the \\ Department of Orthodontics \\ University of Louisville School of Dentistry \\ In Partial Fulfillment of the Requirements \\ for the Degree
}

Masters in Oral Biology

August 2012 


\title{
THE PATIENT'S VIEW OF ORTHODONTIC TRAINING REQUIREMENTS AND THE INFLUENCE OF BOARD CERTIFICATION OR A MASTER'S DEGREE ON THEIR CHOICE FOR AN ORTHODONTIST
}

\author{
By Justin Trisler \\ BSc Berry College, 2002 \\ DMD University of Alabama Birmingham School of Dentistry, 2006
}

A Thesis Approved on

June 6, 2012

By the following Thesis Committee

\begin{tabular}{c} 
David Tasman, DMD \\
Thesis Director \\
\hline Eric Bednar, DDS, MS
\end{tabular}

Sunita Chandiramani, DMD, MS 


\section{DEDICATION}

This thesis is dedicated to my family, who has afforded me the opportunities in education that have shaped my values and thinking. To God, who has blessed me with a desire to achieve the best $\mathrm{He}$ has for me, and a mind to be able to accomplish it. A special thanks to my wife, Kelly Trisler who has endured countless hours of studies during these educational pursuits. Her ceaseless effort and much needed help has brought me to the conclusion of this journey. 


\section{ACKNOWLEDGEMENTS}

I would like to thank all of my committee members, Dr. David Tasman, Dr. Eric Bednar and Dr. Sunita Chandiramani for their direction, guidance and aid that they have tirelessly given me in development of this project. I would also like to acknowledge Alex Cambon for his work and help in developing a statistical protocol for analyzing my research data and especially his help understanding that protocol and the results. I would finally like to thank Eric Harris for his help collecting data and entering the results into the spreadsheet. 


\begin{abstract}
THE PATIENT'S VIEW OF ORTHODONTIC TRAINING REQUIREMENTS AND THE INFLUENCE OF BOARD CERTIFICATION OR A MASTER'S DEGREE ON THEIR CHOICE FOR AN ORTHODONTIST

Justin Trisler, DMD

June 6, 2012
\end{abstract}

Competition for orthodontic patients is at an all time high. Ways to differentially market an orthodontic practice are essential in attracting patients. It is hypothesized that the patients don't understand the extra training that an orthodontist must complete and that being board certified by the $\mathrm{ABO}$ or completing a Master's degree does not make an orthodontic practice more attractive. A sample of 204 perspective patients was surveyed. 4 participants were resurveyed. Participants were asked to quantify the education of a general dentist and an orthodontist and use a VAS scale to measure their perception of differently qualified orthodontists and a general dentist providing orthodontics. Those surveyed accurately determined the amount of education an orthodontist and general dentist complete and perceived the orthodontist with the most credentials as most favorable. They also favored the general dentist providing orthodontics. A Master's degree was only somewhat favored. Most questions were found valid. 


\section{TABLE OF CONTENTS}

PAGE

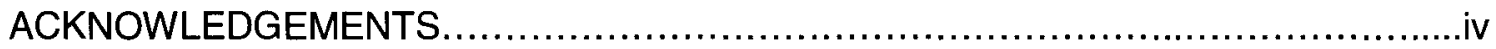

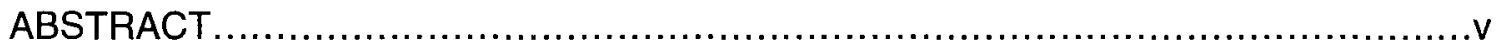

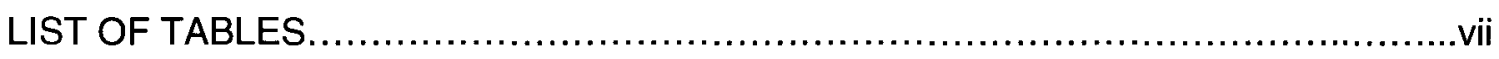

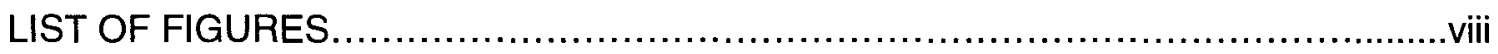

CHAPTER

I. INTRODUCTION

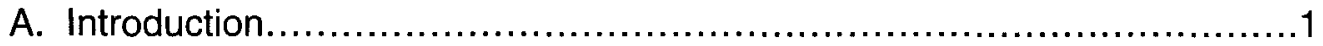

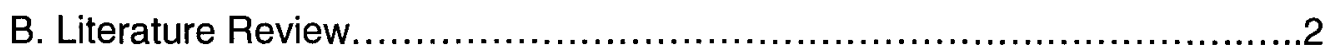

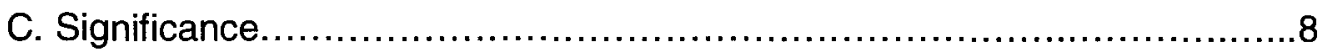

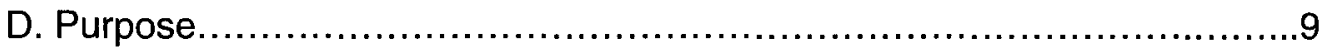

E. Hypotheses...................................................................

II. METHODS AND MATERIALS
A. Sample. 11
B. Inclusion/Exclusion Criteria. 11

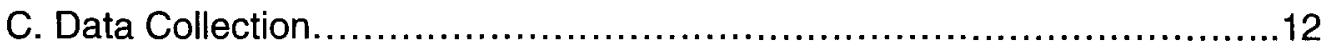

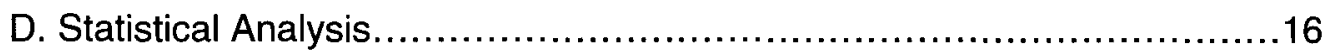

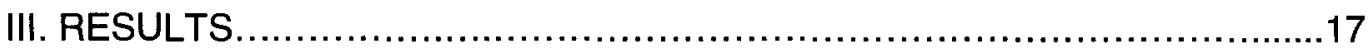

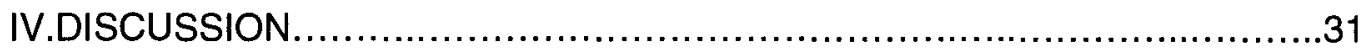

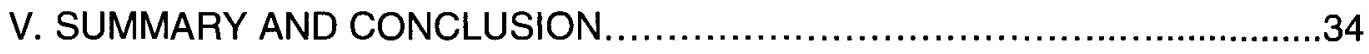

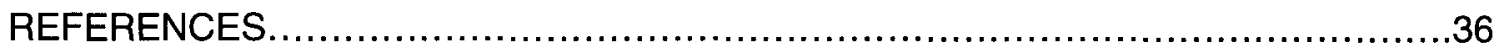

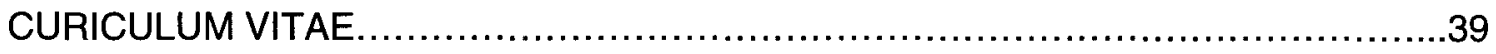




\section{LIST OF TABLES}

TABLE

PAGE

1a. Categorical Demographic Characteristics

1b. Numerical Characteristics

2. Comparison of Perceived Education - Dentist vs. Orthodontist

3a. Pairwise Comparisons between VAS scores for ProvidersMean/Median of Differences and P-Values

3b. Pairwise Comparisons between VAS scores for providers -

Difference in Means and 95\% Confidence Intervals

3c. Comparison of Each Provider to 3

22

4. Agreement Statistics

26 


\section{LIST OF FIGURES}

FIGURE

PAGE

1. Survey Inclusion/Exclusion Questions 12

2. Survey Educational Requirements 13

3. Survey Comparison of orthodontic providers 14

4. Distribution of difference between perceived average general dentist total education and perceived average orthodontist total education $\quad 22$

5. Distribution of difference between provider 2 and 4

6. Distribution of difference between provider 2 and 5

7. Distribution of difference between provider 3 and $4 \quad 24$

8. Distribution of difference between provider 2 and 5

9. Distribution of difference between provider 4 and 5

10. Concordance Correlation for Age question 26

11. Concordance Correlation for orthodontist post-college question 27

12. Concordance Correlation for general dentist post-college question 27

13. Concordance Correlation for general dentist college question 28

14. Concordance Correlation for provider \#2 question 28

15. Concordance Correlation for provider \#3 question 29

16. Concordance Correlation for provider \#4 question 


\section{CHAPTER 1}

\section{INTRODUCTION}

\section{A. Introduction}

In recent years there has been an increase in the number of dental schools and orthodontic programs that have expanded, opened, or are being planned.[1] As the field of dentistry as a whole faces increasing competition due to the increasing number of graduates, an increasing number of providers besides orthodontists are beginning to offer orthodontic services. The specialty of orthodontics is also becoming more competitive in certain geographical areas. For most practices successful marketing, both internal and external, has become essential to building a practice.

Orthodontists are more so now than ever looking to differentiate themselves amongst their colleagues and general dentists to market their practice. One of the ways an orthodontist can promote differentiation through education is by having a Master's degree. Another way to differentiate an orthodontist amongst his peers and general dentists is by obtaining board certification through the American Board of Orthodontics. In recent years, the requirements for board certification have decreased and the number of board certified orthodontists has gone up. Although these accomplishments may differentiate an orthodontist amongst his peers, little to no research has looked at whether patients recognize 
these credentials and use them in their treatment decisions when choosing an orthodontist.

New dental companies such as Invisalign ${ }^{\circledR}$ are also marketing and training general dentist in orthodontic procedures and general dentist can even obtain their own board certification in orthodontics through the National Board of Orthodontics. Can patients also spot these providers that do many of the same procedures as those who went through an orthodontic residency for two to three years?

\section{B. Literature Review}

According to recent data, 4,873 students graduated from dental school in 2010.[2] In the past 10 years, Nova Southeastern University, University of Nevada, and AT Still University of Arizona have all opened new dental schools. Many other schools such as the University of Louisville have increased their class sizes. In the past 2 to 3 years, the ADA has granted initial accreditation and classes have begun at the dental schools of Midwestern University in Arizona and Illinois, Western University, Lake Erie College of Osteopathic Medicine (LECOM), East Carolina, and Roseman University. In the next 2 to 3 years, the University of New England and AT Still University in Missouri plan to open dental schools and begin classes. In the next 5 years, LECOM plans to open another dental school in Pennsylvania. States such as New Mexico, Kansas, and Wisconsin are currently looking at opening dental schools in the future.[3] 
In 2010 there were 290 graduates of orthodontic residencies.[2] The numbers of orthodontic residency programs have also been on the rise in the past 10 years. AT Still University of Arizona, Roseman University, Seton Hill, and Nova have all begun orthodontic programs.[1] Many of these newly opened dental schools could also plan on adding orthodontic residency programs in the future.

Back in the year 2000 , only 4,171 students graduated dental school and 238 graduated orthodontic residencies.[2] This is an increase of about $17 \%$ for dental school graduates and $22 \%$ for orthodontists from 2000 to 2009 . By contrast, the population in the United States grew 9.7\% from 2000 to 2010, with the population of children age $5-17$ only growing by $1.9 \%$.[4]

Not only has the number of new dentist and orthodontist entering the market substantially risen in the last 10 years, but the current economic climate has forced many existing practitioners to delay retirement to recover lost retirement assets. These two factors along with other reasons have increased competition for prospective patients among providers. This increasing competition has lead more general practitioners (GPs) to look for new avenues for marketing their practices. One of ways GPs can increase revenue and market to patients is by offering orthodontic services. As more GPs begin to offer orthodontic services and the numbers of current orthodontists increase, marketing to prospective orthodontic patients is becoming increasing important to building a practice.

According to estimates, Americans are subjected to more than 2,000 marketing messages per day.[5] With this cloud of influences surrounding prospective 
orthodontic patients, marketing for orthodontists in today's competitive market is essential for success. Marketing an orthodontic practice can be defined as a mind-set and a set of activities; a practice's total preparedness to deliver, position, and promote services of value, based on knowledge of needs and demands of patients and referrers.[6] There are two major forms of marketing an orthodontic practice: Internal marketing and external marketing.[7] Internal marketing focuses on existing patients and their experiences and also works to build staff interest and investment in the practice. The orthodontist needs to set the internal marketing tone and pace for the practice with the staff mirroring their example. Internal marketing works by turning each patient into a referral source. A practice can position itself to stand out in a competitive market through a range of services, fee structure, office design, personnel, and communications.[6] The mission of the practice should be defined from the patient's perspective, not the practitioners. Perception usually is reality.

External marketing is promotional communication directed toward potential patients and referral sources and includes advertising, sponsorships, sales promotions, and public relations. In 1977, the US Supreme Court in Bates $v$ The State Bar of Arizona ruled that restraints on advertising by professionals violated the right to free speech protected under the First Amendment of the Constitution [8], and in 1979 the American Dental Association amended its code of ethics to remove restrictions on advertising.[9] A study in 2005 done by the Journal of Clinical Orthodontics found that $20.4 \%$ of American orthodontist advertised in local newspapers, $13.1 \%$ used direct mail promotions, $5.6 \%$ advertised on local 
radio, and 3.9\% advertised on local television.[10] However, a recent study by Edwards, et al. $14 \%$ to $24 \%$ of orthodontic patients surveyed felt that advertising orthodontist would offer a lower quality of care than non-advertising orthodontist with newspaper, magazine, and direct mail advertisements viewed more favorably than radio, television, and billboard advertisements.[11]

The American Association of Orthodontists (AAO) conducted their own consumer study in 1997. Their sample population was female heads-of-households with children that were 25-44 years of age and had household incomes above $\$ 30,000$. The AAO's conclusions from this study gathered that general dentists are the primary referral source for orthodontists and insurance also played a key factor in selecting an orthodontist. $92 \%$ of this population seemed to understand the difference between the services provided by orthodontists and general dentists, but $20 \%$ said they received orthodontic care from a general dentist. During this period only half of consumers had heard advertisements about orthodontic care in the media.[14]

Walley et al. also conducted a survey in 1999 that addressed patient and parent preferences for orthodontic practices. Their results revealed that the reputation of the practitioner was the most important factor along with the level of caring attitude the office projected. A close proximity to the patient's home was also deemed important. The price of the orthodontic treatment was found to be not as important as the payment plans offered.[15] 
Since 1997, the AAO has conducted numerous advertising campaigns in print, web, and visual media. The two recent campaigns, More Than a Smile (20062008) and Puzzle (2009-2011), were also based on consumer research of a similar population as the group in their 1997 study. The AAO now found that about $75 \%$ of consumers in focus groups were not aware of non-specialists providing orthodontic treatment. Consumers didn't necessarily understand that someone who does orthodontic treatment may necessarily be an orthodontist; and that if their family dentist said they could do their orthodontic treatment, 112 of 117 were open to that. Reasons cited included were the established relationship with their general dentist, a perceived lower cost than a specialist, and that it would be "one stop shopping" (the doctor could handle both orthodontic treatment and general dental needs.[16]

Since 2006, the AAO has used its advertising campaigns to convey the message that orthodontists have an additional 2 to 3 more years of education beyond dental school. This message was recently retested with their current campaign My Life. My Smile. My Orthodontist. ${ }^{\mathrm{sm}}$ and was found to still have relevance and impact.[17]

Because perspective patients may not recognize an orthodontist as having additional education and training, strategic marketing is very important to help attract and educate patients. One way to develop a successful marketing strategy is through a Strengths, Weaknesses, Opportunities and Threats (SWOT) analysis.[12] This can be done by conducting marketing research amongst both local internal and external audiences. Lingg conducted a recent SWOT analysis 
as a pilot study and had prospective patients rate practice factors.[13] This study was just to validate the survey, but the follow-up study should be coming soon. There are many ways practitioners can position themselves in a competitive market. Head-to-head competition is usually too costly in terms of time, effort, and resources. Instead, choose an identity that the market desires and possibly doesn't already exist. Be careful in choosing a practice identify based solely on excellent quality of treatment. Technical competence is expected by patients and referring dentist.[5] One type practice identity could be as the recognized authority by having more academic qualifications than competitors such as a Master's degree or obtaining board certification through the American Board of Orthodontist (ABO).

An orthodontist can obtain their board certification through the ABO. The ABO was founded by 7 orthodontists in 1929 under the guidance of Albert Ketcham. To receive their certification an orthodontist must successfully complete 3 phases. Phase I involves graduating from an American accredited orthodontic residency. Phase II is a written exam given by the ABO, and Phase III involves presenting completed cases to current ABO members. As of $2004,31 \%$ of all AAO members who have been practicing long enough to do so are boardcertified and over $90 \%$ of final-year residents have participated in Phase II (written) examinations since 1995.[18] In 2007, in an effort to increase board certification among young orthodontists, the ABO began to offer a new Phase III initial certification exam for graduating residents. This examination involves the presentation of 6 cases treated in residency programs and evaluated according 
to $A B O$ standards. New graduates are even allowed to submit 3 cases completed during residency to be used to fulfill the board's requirement of 6 cases at a later date. Upon completion of the Phase III exam, graduates will be issued a 10 year time limited certification.[19]

\section{Significance:}

Within the last few years the AAO participated in ad campaigns designed to educate the general public about the specialty of orthodontics. Their goal is continued reinforcement that orthodontists have an additional 2 to 3 years more education beyond dental school than general dentists. There is very limited published current literature to validate if these ad campaigns have been effective. There is also limited current literature on patient and parent preferences for orthodontic practices in the current market and if patients perceive additional education or certifications as being a recognized authority in the field. If an orthodontist is viewed as an authority in their field, patients should preferentially seek treatment in their office.

Very few general dentists were providing orthodontic services before treatments such as Invisalign ${ }^{\circledR}$ and Six Month Smiles ${ }^{\circledR}$ appeared in recent years. Invisalign ${ }^{\circledR}$ is a series of clear plastic aligners (trays) worn in sequence to straighten teeth. The movements are set up by computer software and the aligners are fabricated us CAD/CAM technology.[20] Six Month Smiles ${ }^{\circledR}$ is a form of orthodontics that only straightens us front maxillary teeth using nickel-titanium wires and usually 
takes 6 months or less.[21] The number of general dentists providing orthodontic services is increasing due to increasing numbers of recent graduates, larger student loans to repay, and less technical orthodontic treatment modalities.

Orthodontists need effective strategies for marketing to perspective patients in competitive markets and ways to differentiate themselves as specialist to attract potential patients.

This study may also aid in the decision of orthodontic residents to pursue board certification through the $\mathrm{ABO}$ or a Master's degree (when optional during their time in residency).

\section{Purpose:}

This study has the following aims:

- To determine if the general orthodontic patient population correctly knows the education levels for general dentists and orthodontists

- To determine if there is a difference in preference for orthodontic treatment among orthodontists with more credentials

- To determine if there is a difference in preference for orthodontic treatment from an orthodontist or a general dentist providing orthodontics 


\section{E. Hypothesis:}

Null Hypotheses:

1. There is no difference in perceived education between general dentists and orthodontist

2. There is no preferred provider for providing orthodontic treatment based on print advertisements

Alternative hypotheses:

1. There is a difference in perceived education between general dentists and orthodontist

2. There is a preferred provider for providing orthodontic treatment based on print advertisements 


\section{CHAPTER II}

\section{METHODS AND MATERIALS}

\section{A. Sample:}

The IRB number for this study is 11.0549 and it received exemption status. The sample population was taken from patients or parents/relatives of patients at the University of Louisville Orthodontic department. The participates were selected at random by being asked to fill out a survey as part of the registration packet for a new patient screening or being asked to fill out a survey while seated in the waiting room. A select number of participants were asked to take the same survey at the next appointment.

\section{B. Inclusion/Exclusion criteria:}

In order to best quantitatively analyze this study, research subjects that were selected to complete this study qualified using the following inclusion/exclusion criteria:

1. Subject had to be 18 or older

2. Subject had to have no previous formal dental training 
Figure 1. Inclusion/Exclusion Questions

Please complete the following Survey. Completion of this survey is completely voluntary and should take only a couple of minutes.

Age:

Sex: $M / F$

Do you have any training in the dental profession? $\mathrm{Y} / \mathrm{N}$

If yes, please explain

Race/Ethnicity: Caucasian African American Asian Hispanic

Other

\section{Data collection:}

Before participating in this study, all subjects were informed of the subject matter involved in the questionnaire and given written consents and the survey questionnaire. By filling out a questionnaire, the subjects gave their consent for the study. Subjects were only approached in the Orthodontic/Pediatric waiting room of the University of Louisville.

Subjects were first asked to quantify the educational requirements of general dentists and orthodontists for both College and Post-College. 
Figure 2. Educational Requirements

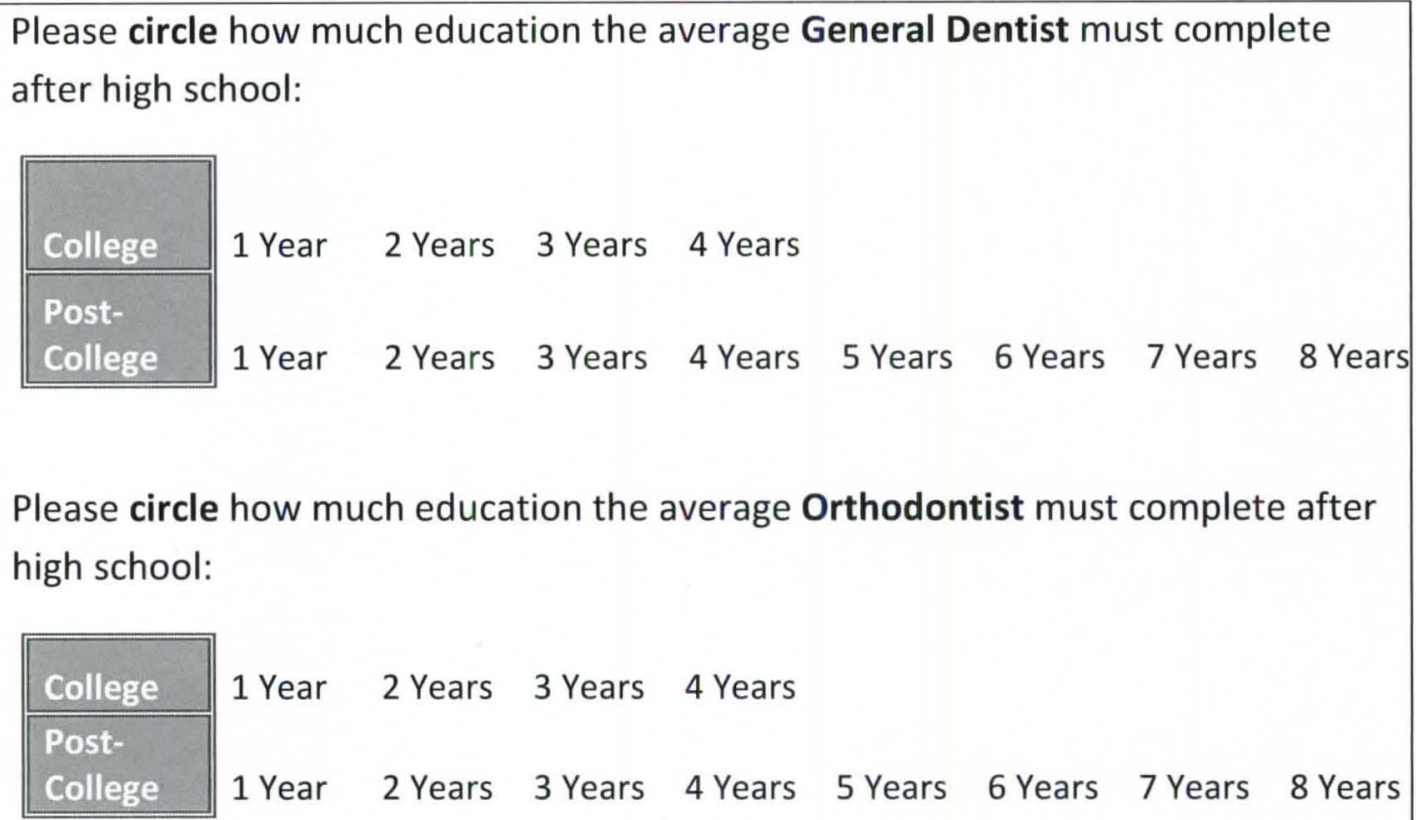

Please circle how much education the average Orthodontist must complete after high school:

Subjects were then given an advertisement for an orthodontic provider and then asked to compare 4 additional provider advertisements to the first advertisement using a visual analog scale(VAS). They used the VAS scale to rate if they were more or less likely to see the provider if cost and convenience were the same. Provider \#2 was an orthodontist with a Master's degree. Provider \#3 was an orthodontist with board certification through the American Board of Orthodontics. Provider \#4 was an orthodontist with both a Master's degree and Board Certification. Provider \#5 was a general dentist providing orthodontic, restorative and cosmetic procedures who also had board certification through the National Board of Orthodontics. Subjects were also given a blank to fill in why they selected their answers. 
Figure 3. Comparison of orthodontic providers

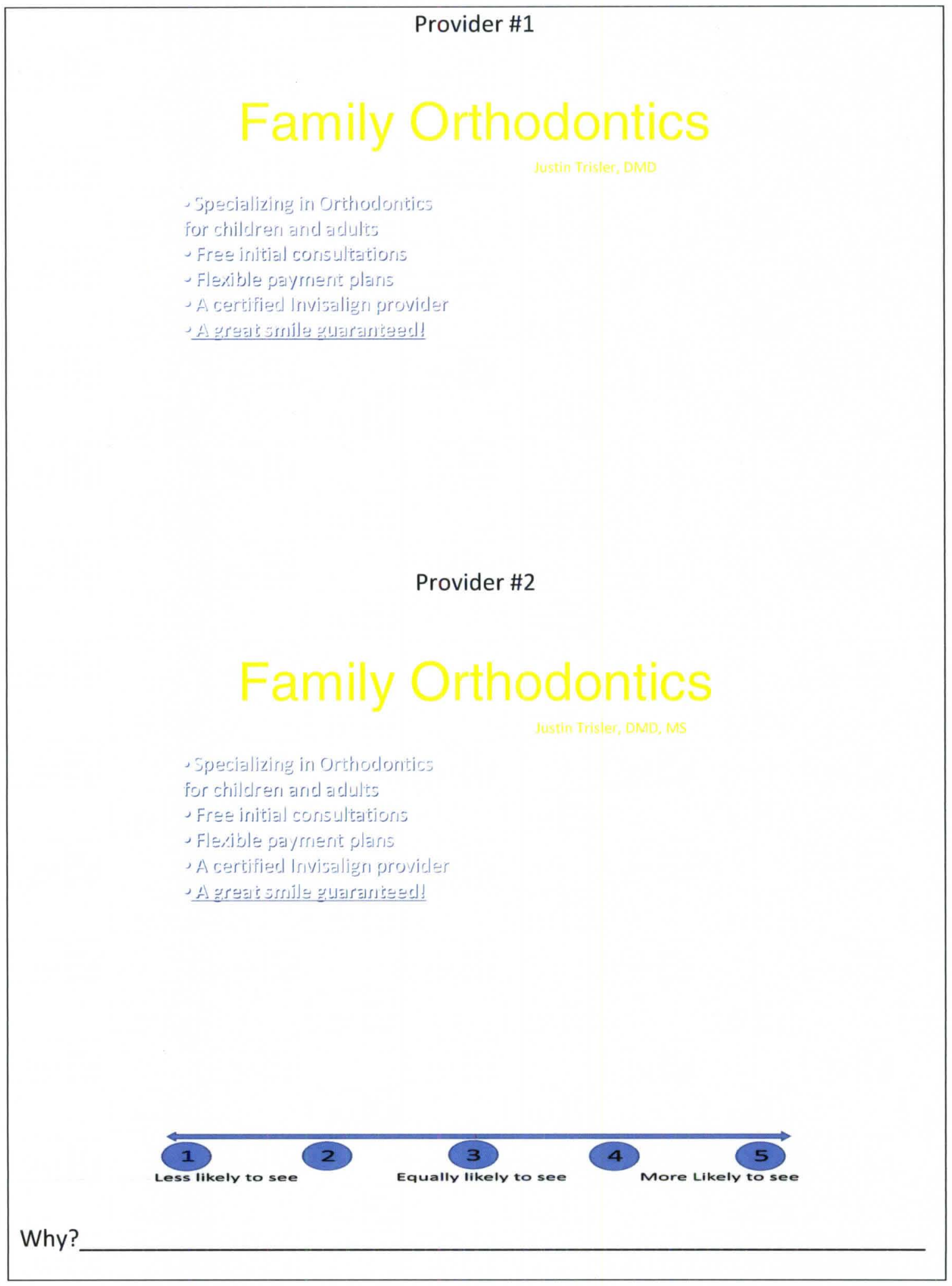




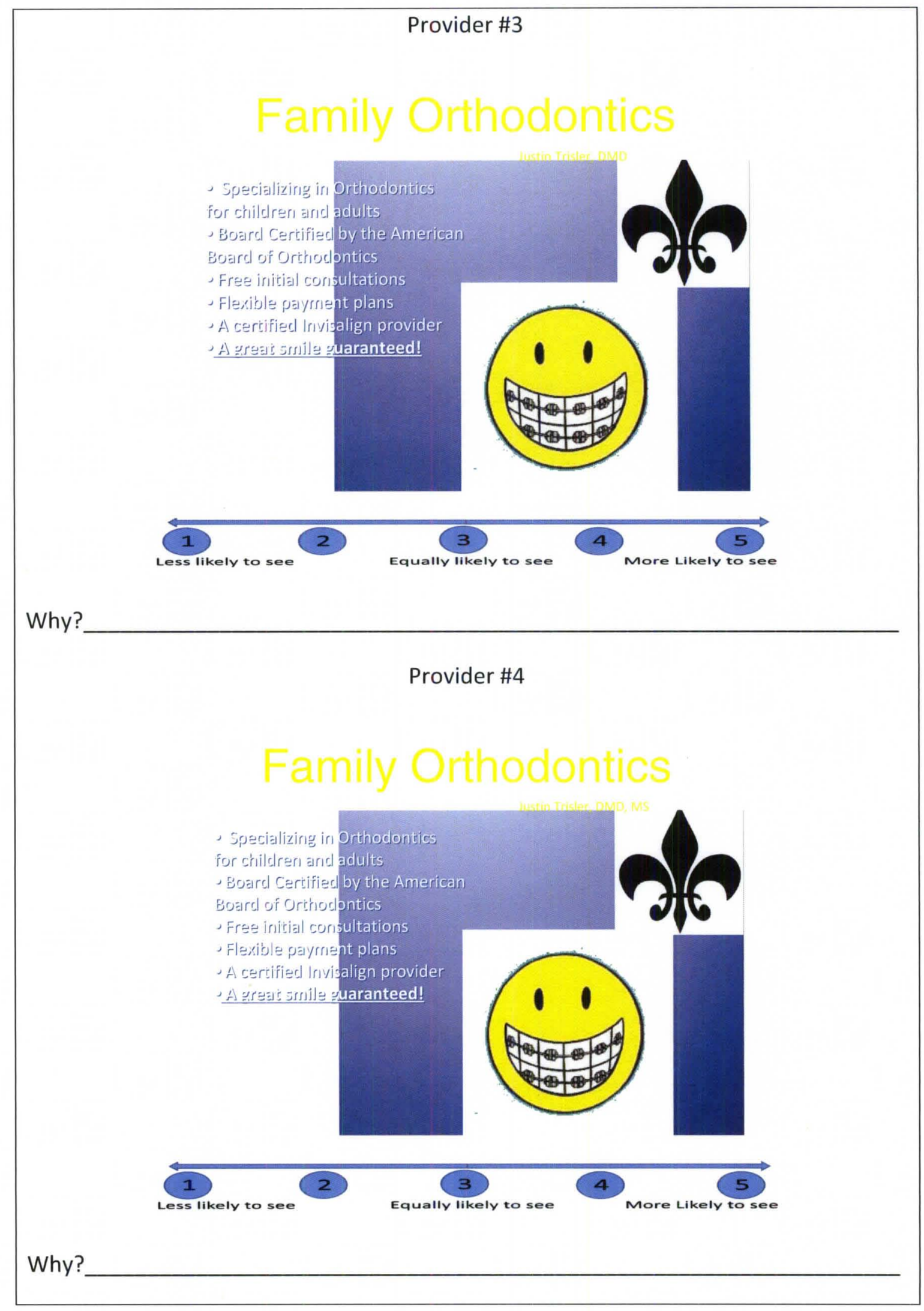


Provider \#5

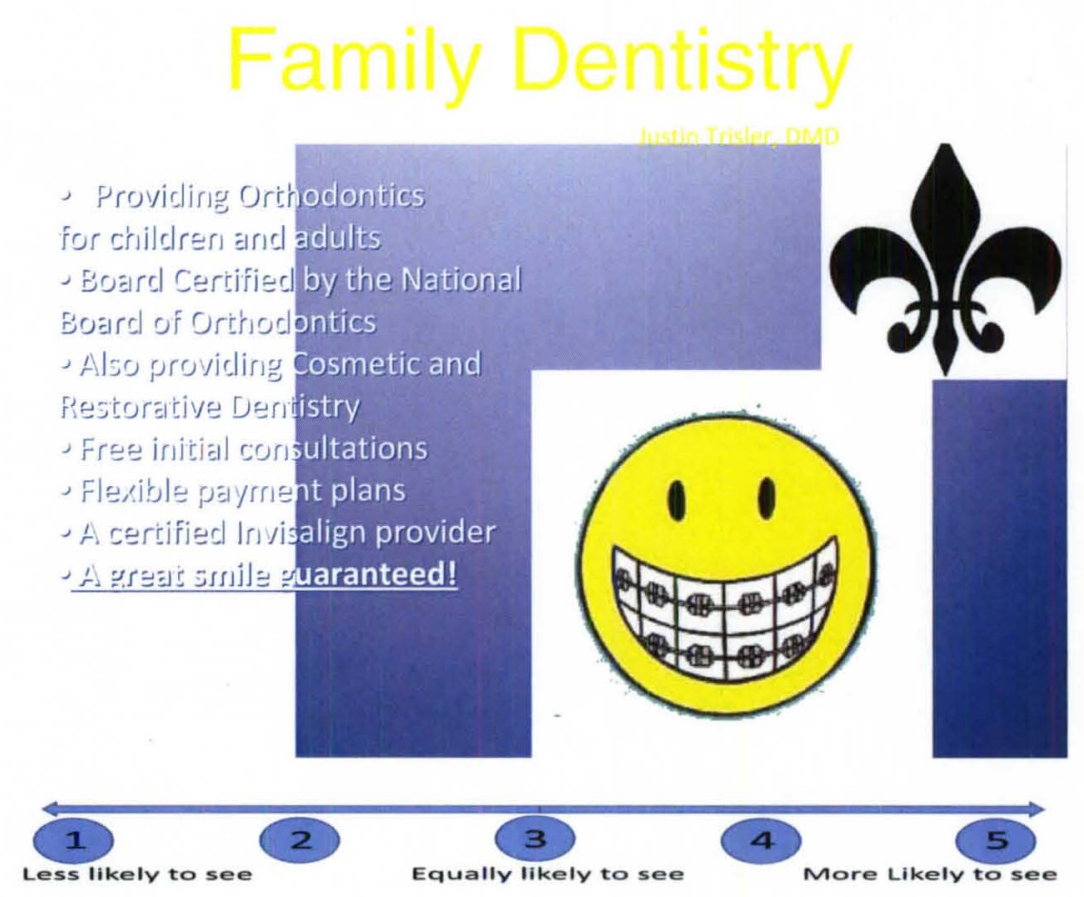

Why?

D. Statistical analysis:

All paired comparisons were made using paired t test and the Wilcoxon Signed

Rank Test. The intraclass correlation coefficients were calculated used for agreement statistics. Percent agreement, Spearman's correlation coefficient, and the Concordance Correlation Coefficient were also calculated. 95\% Confidence Intervals are also provided for the Concordance Correlation Coefficient where possible. 


\section{CHAPTER III}

\section{RESULTS}

The data consisted of 191 subjects, 149 of which were female, 41 of which were male, and one with missing gender. The mean age was 42 , the median age was 41 , and the age ranged from 18 to 76 , with 41 missing. There were 143 subjects who reported Caucasian race, 28 African American, 10 reporting other ethnic groups, and 10 missing.

Table 1 gives distribution of subject characteristics by gender and ethnic group.

Table 1a: Categorical

Demographic

Characteristics.

\begin{tabular}{lccc}
\hline Characteristic & Level & $\mathrm{N}$ & $\%$ \\
\hline Sex & & & \\
& Female & 149 & 78.4 \\
& Male & 41 & 21.6 \\
Age & Missing & 1 & \\
& & & \\
& $18-29$ & 14 & 9.3 \\
& $30-39$ & 50 & 33.3 \\
& $40-49$ & 54 & 36.0 \\
& $50-59$ & 19 & 12.7 \\
Race & $60+$ & 13 & 8.7 \\
& Missing & 41 & \\
& & & \\
& AA & 28 & 15.5 \\
& Asian & 4 & 2.2 \\
& Caucasian & 143 & 79.0 \\
& Hispanic & 2 & 1.1 \\
& Other & 4 & 2.2 \\
& Missing & 10 & \\
\hline & & &
\end{tabular}


Table $1 \mathrm{~b}$ report numerical characteristics, including age, sex, and also PS-IS (progressive surfaces measurement minus initial surfaces measurement).

Subjects were asked to estimate average total education for a general dentist and for an orthodontist, in years. In addition they were asked to rate, in VAS scale, how likely they would see providers with the following advertisements compared to a base orthodontic advertisement:

Provider 2: Orthodontic advertisement with an orthodontist holding a Master's degree.

Provider 3: Orthodontic advertisement with an orthodontist having ABO certification.

Provider 4: Orthodontic advertisement with an Orthodontist holding a Master's degree and having $\mathrm{ABO}$ certification.

Provider 5: General dental practice advertisement for Orthodontic services with the general Dentist having a form of board certification through the National Board of Orthodontics. 
Table 1b: Numerical Characteristics

\begin{tabular}{cccccccc} 
Variable & $\mathrm{N}$ & Mean & $\begin{array}{c}\text { Std } \\
\text { Dev }\end{array}$ & Median & Min & Max & N Miss \\
\hline Subjects & 191 & & & & & & \\
Age & 150 & 42.1 & 11.08 & 41 & 18 & 76 & 41 \\
GP_COL & 139 & 3.83 & 0.56 & 4 & 1 & 4 & 52 \\
GP_Post & 148 & 4.09 & 1.76 & 4 & 1 & 8 & 43 \\
GP_ED & 182 & 7.18 & 2.40 & 8 & 1 & 12 & 9 \\
OR_COL & 125 & 3.82 & 0.52 & 4 & 2 & 4 & 66 \\
OR_POSt & 167 & 5.22 & 1.96 & 5 & 1 & 8 & 24 \\
OR_ED & 181 & 8.67 & 2.52 & 9 & 2 & 12 & 10 \\
PROVIDER_2 & 145 & 3.21 & 1.01 & 3 & 1 & 5 & 46 \\
PROVIDER_3 & 116 & 3.59 & 1.06 & 4 & 1 & 5 & 75 \\
PROVIDER_4 & 125 & 4.01 & 0.86 & 4 & 1 & 5 & 66 \\
PROVIDER_5 & 136 & 3.82 & 1.24 & 4 & 0 & 5 & 55 \\
\hline
\end{tabular}

For question 1, (do the subjects believe that general dentists and orthodontists have the same average level of education), the answer is no. The perceived average education for a general dentist was significantly lower than that for an orthodontist (mean difference $=-1.5$ years education, median difference -2 years education, standard deviation 2.1 years education). The $p$-value was $<0.0001$ using both paired t-test and signed rank test. Table 2 shows overall results, as well as results stratified by gender and age. The results stratified by gender are consistent with the overall results. The results stratified by age show that there is less of a difference in perceived education among older subjects (those aged 5059 and those 60 and older) as well as perhaps the 18-29 age group. 
Table 2: Comparison of Perceived Education - Dentist vs. Orthodontist.

\begin{tabular}{lccccc}
\hline \multirow{3}{*}{ Gender } & & mean $(95 \% \mathrm{Cl})$ & median & paired $\mathrm{t}$ & Signed Rank \\
\cline { 3 - 6 } & Overall & $-1.52(-1.82-1.21)$ & -2 & $<.0001$ & $<.0001$ \\
& Male & $-1.55(-2.32--0.79)$ & -2 & 0.0002 & $<.0001$ \\
\cline { 3 - 6 } Age & Female & $-1.52(-1.85--1.18)$ & -2 & $<.0001$ & $<.0001$ \\
& & & & & \\
& $18-29$ & $-1.00(-2.12-0.12)$ & -1 & 0.074 & 0.125 \\
& $30-39$ & $-2.13(-2.77--1.48)$ & -2 & $<.0001$ & $<.0001$ \\
& $40-49$ & $-1.67(-2.20--1.13)$ & -2 & $<.0001$ & $<.0001$ \\
& $50-59$ & $-0.79(-1.68-0.099)$ & -1 & 0.078 & 0.0225 \\
& $>60$ & $-0.42(-2.38-1.55)$ & -1 & 0.649 & 0.022 \\
\hline
\end{tabular}

Abbreviations: paired $t-p$-value for paired $t$ test; Signed Rank $-p$-value for Wilcoxon Signed Rank Test; $95 \% \mathrm{Cl}-95 \%$ Confidence Intervals for the mean.

Tables $3 a$ and $3 b$ show results for questions 2 (comparing VAS scores for Providers 2 through 5). There was too much missing data to make an overall comparison (see Table 1b), so paired comparisons were made instead. There was a significant difference between VAS scores for Provider 2 and all other providers, with provider 2 having a significantly lower VAS score compared to all other providers. P-values were all less than 0.001 , using paired t-test or Wilcoxon Signed Rank test. Mean differences ranged between -0.4 (between providers 2 and 3) to -0.9 (between providers 2 and 4 ). There was also a significant difference between Providers 3 and 4 , with both $p$-values again less than 0.001 . The mean difference was -0.4 , and there was no median difference. There were no significant differences between providers 3 and 5 or providers 4 and 5 .

Some caution is warranted for the analysis of the second question because of the high percentage of missing data comparisons. Table 3 shows missing data 
for providers 2 through 5 at 46 for provider 2 and a maximum of 75 for provider 3 . When paired comparisons are made, the missing data increases since analysis is only done when both paired observations are not missing. For example 82 out of the 191 observations were missing for the paired comparison analysis between VAS scores for providers 3 and 4. This analysis assumes that the data were missing completely at random.

Table 3c compares each provider to see if the perceived ranking is significantly different from 3 . The value 3 is the assigned value of the control, Provider 1 , that all other providers were compared to. All providers 2 through 5 are significantly different from 3. Provider 2 has the smallest mean difference from 3 of 0.21 , and also the largest $p$-values ( 0.14 for $t$ test, and 0.013 for the Wilcoxon test). Note that these mean differences can also be derived from the values for the mean of each provider in Table 1b, simply by adding 3. However Table 3c also provides tests of significance and confidence intervals.

Table 3a: Pairwise Comparisons between VAS scores for Providers Mean/Median of Differences and P-Values

\begin{tabular}{ccccc}
\hline Provider & & 3 & 4 & 5 \\
\hline 2 & mean(t-test p-value) & $-0.44(0.0004)$ & $-0.87(<.0001)$ & $-0.62(<.0001)$ \\
& median(Signed Rank p-value) & $-1(<.0001)$ & $-1(<.0001)$ & $-1(<.0001)$ \\
3 & mean(t-test p-value) & & $-0.38(0.0002)$ & $-0.21(0.077)$ \\
& median(Signed Rank p-value) & & $0(<.0001)$ & $0(0.063)$ \\
4 & mean(t-test p-value) & & & $0.22(0.083)$ \\
& median(Signed Rank p-value) & & & $0(0.140)$ \\
\hline
\end{tabular}


Table 3b: Pairwise Comparisons between VAS scores for providers Difference in Means and 95\% Confidence Intervals

\begin{tabular}{ccccc}
\hline Provider & & 3 & 4 & 5 \\
\hline 2 & mean $(95 \% \mathrm{Cl})$ & $-0.44(-0.68--0.2)$ & $-0.87(-1.04--0.69)$ & $-0.62(-0.89-0.36)$ \\
3 & $\operatorname{mean}(95 \% \mathrm{Cl})$ & & $-0.38(-0.57--0.19)$ & $-0.21(-0.45-0.023)$ \\
4 & mean $(95 \% \mathrm{Cl})$ & & & $0.22(-0.03-0.48)$ \\
\hline
\end{tabular}

Table 3c: Comparison of Each Provider to 3.

Figure 4

\begin{tabular}{|c|c|c|c|c|}
\hline & \multirow[b]{2}{*}{ mean $(95 \% \mathrm{Cl})$} & \multirow[b]{2}{*}{ median } & \multicolumn{2}{|c|}{ P-Values } \\
\hline & & & t-test & Wilcoxon \\
\hline Provider $2-3$ & $0.21(0.04-0.38)$ & 0 & 0.0135 & 0.0125 \\
\hline Provider $3-3$ & $0.59(0.39-0.78)$ & 1 & $<.0001$ & $<.0001$ \\
\hline Provider $4-3$ & $1.01(0.86-1.16)$ & 1 & $<.0001$ & $<.0001$ \\
\hline Provider $5-3$ & $0.82(0.61-1.03)$ & 1 & $<.0001$ & $<.0001$ \\
\hline
\end{tabular}

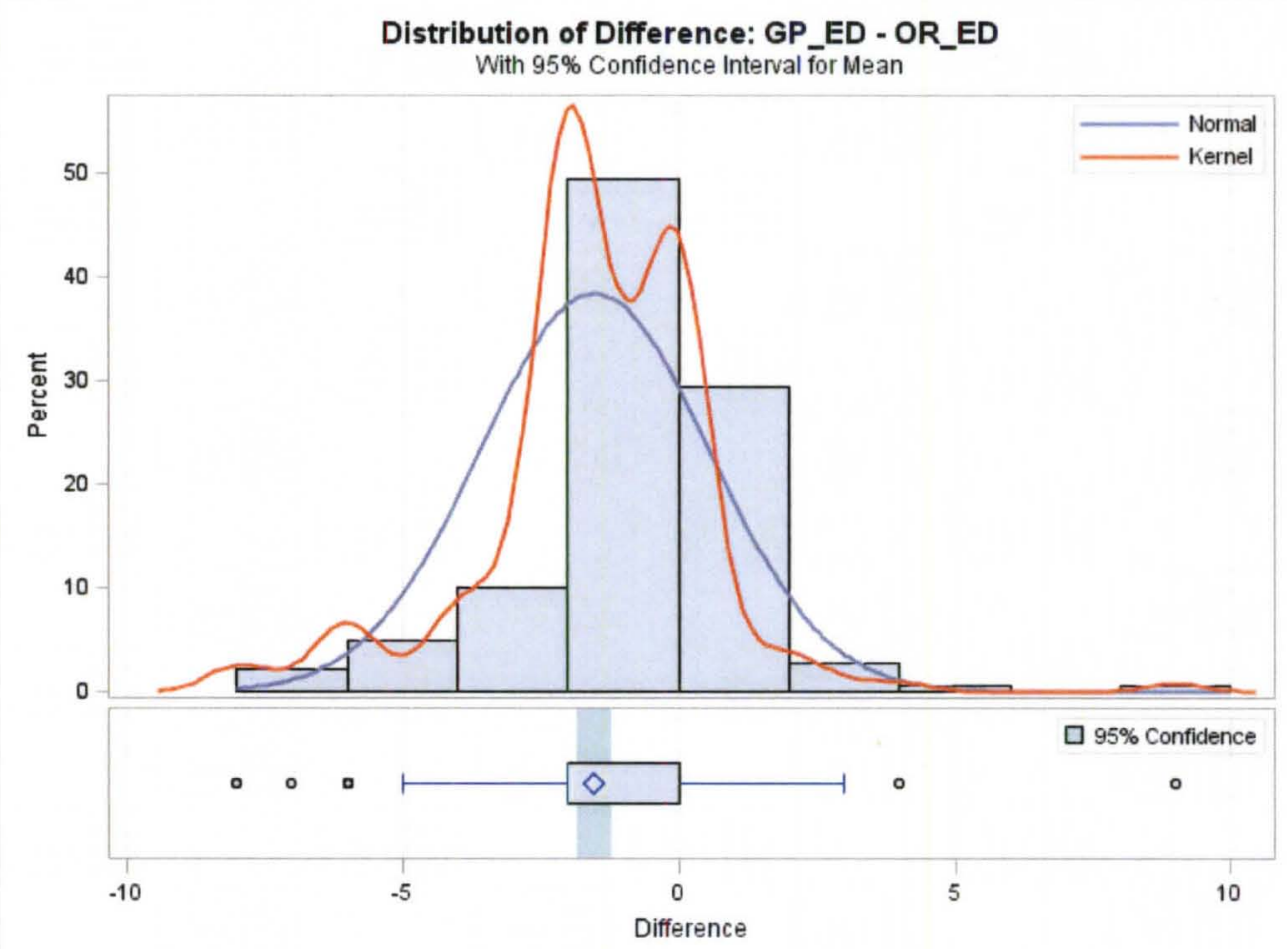

Figure 4: Distribution of difference between perceived average general dentist total education and perceived average orthodontist total education. 95\% Confidence Interval (lower vertical green vertical bar) does not even come close to overlapping 0 . 
Figure 5

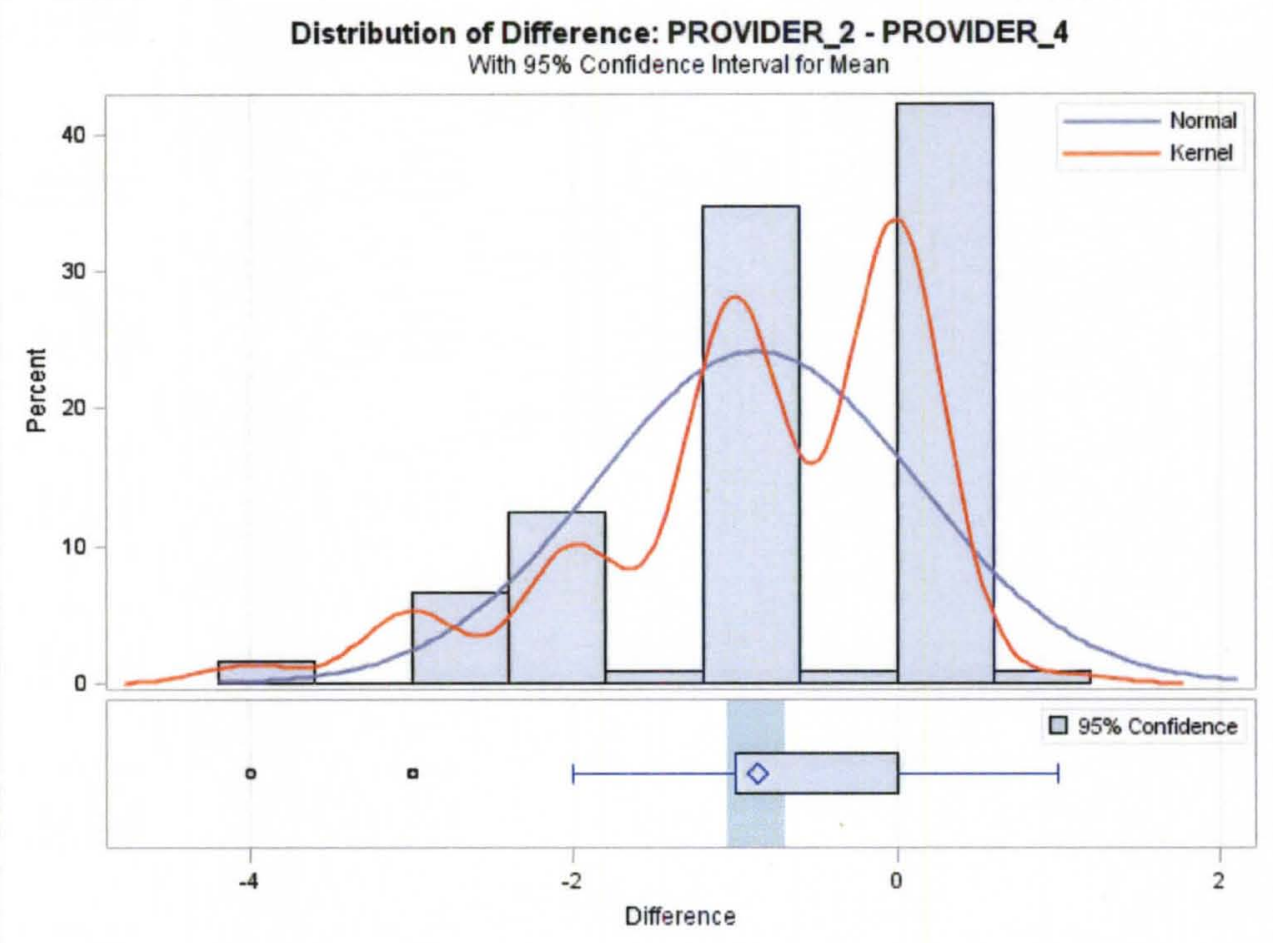

Figure 6

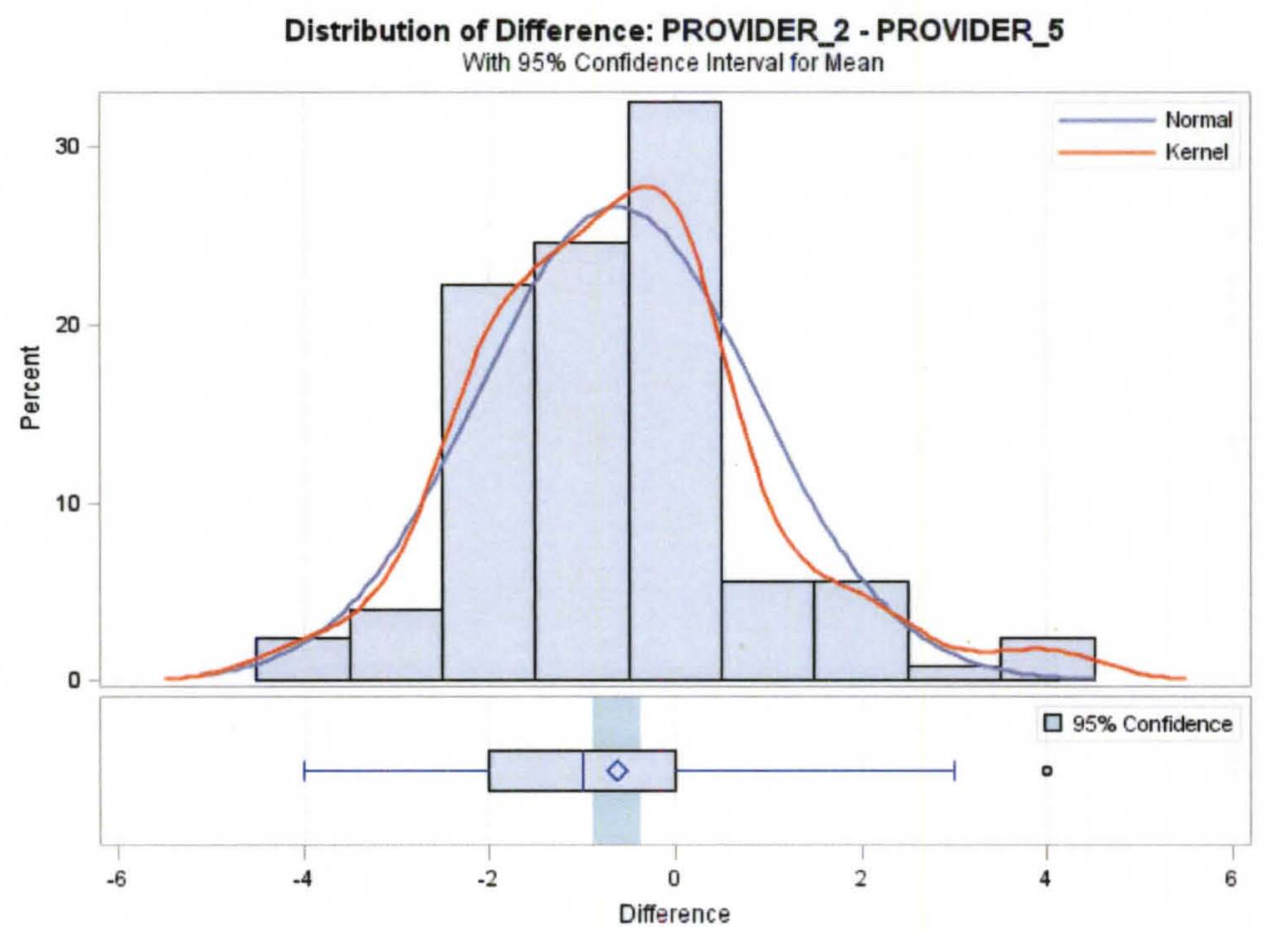


Figure 7

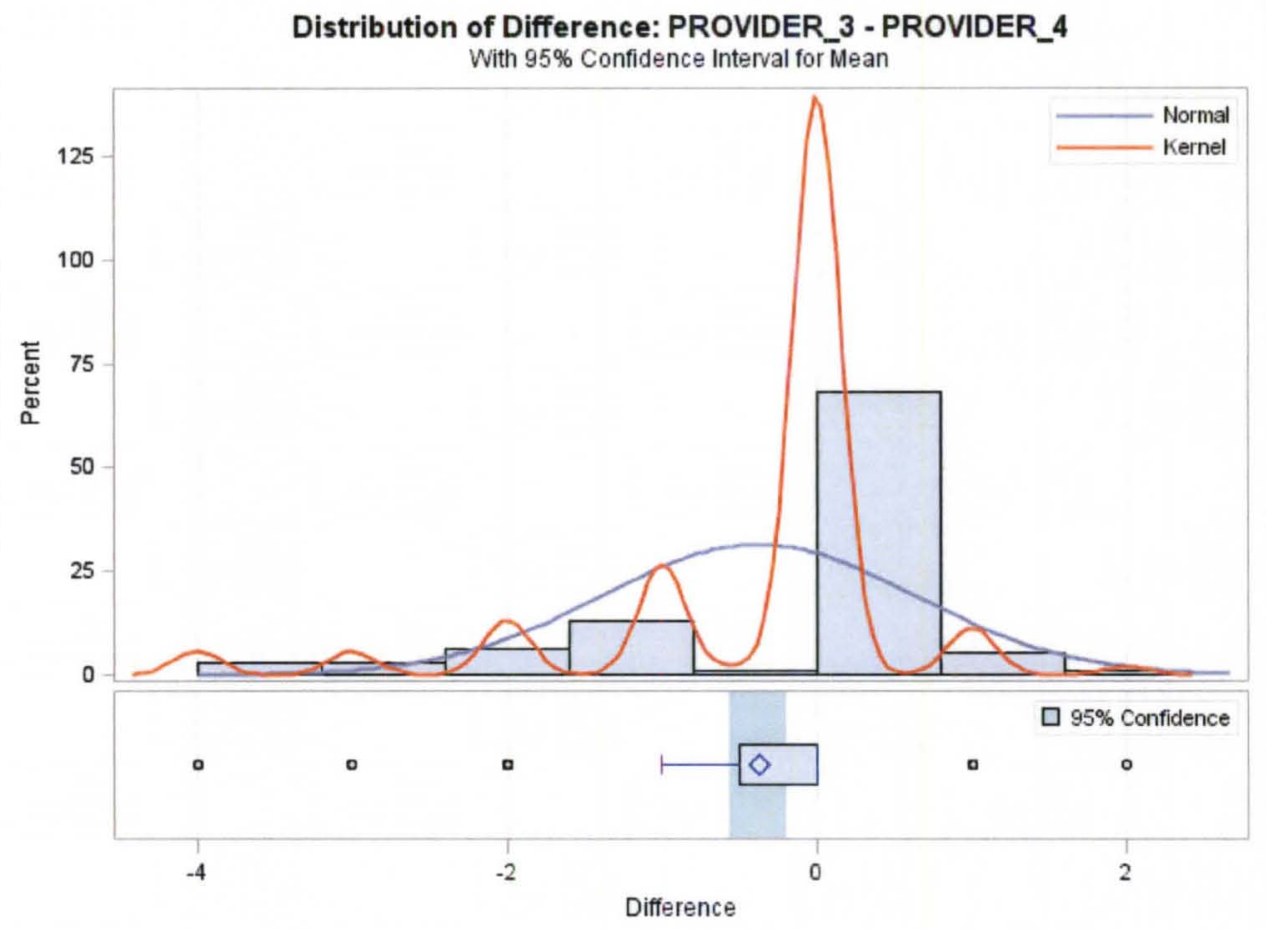

Figure 8

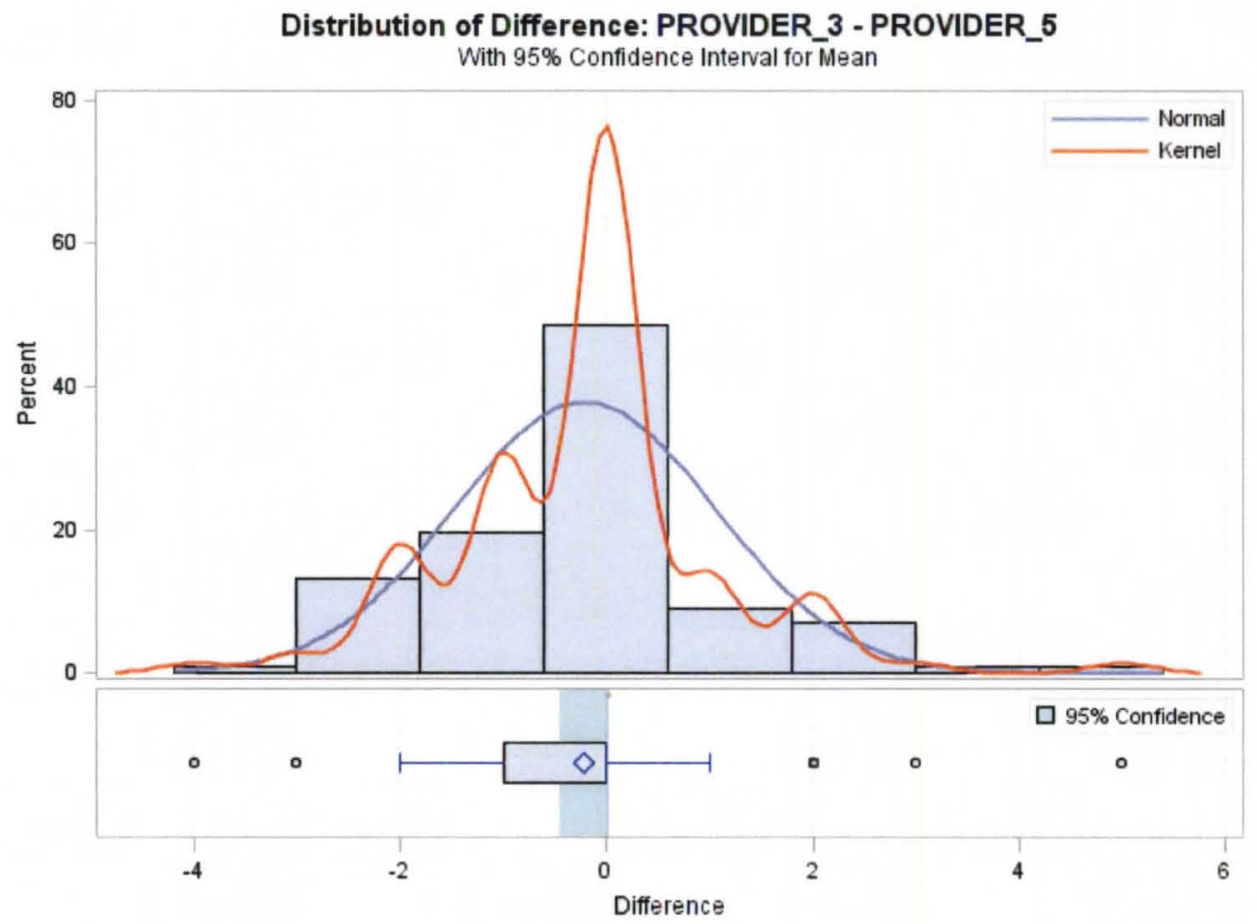


Figure 9

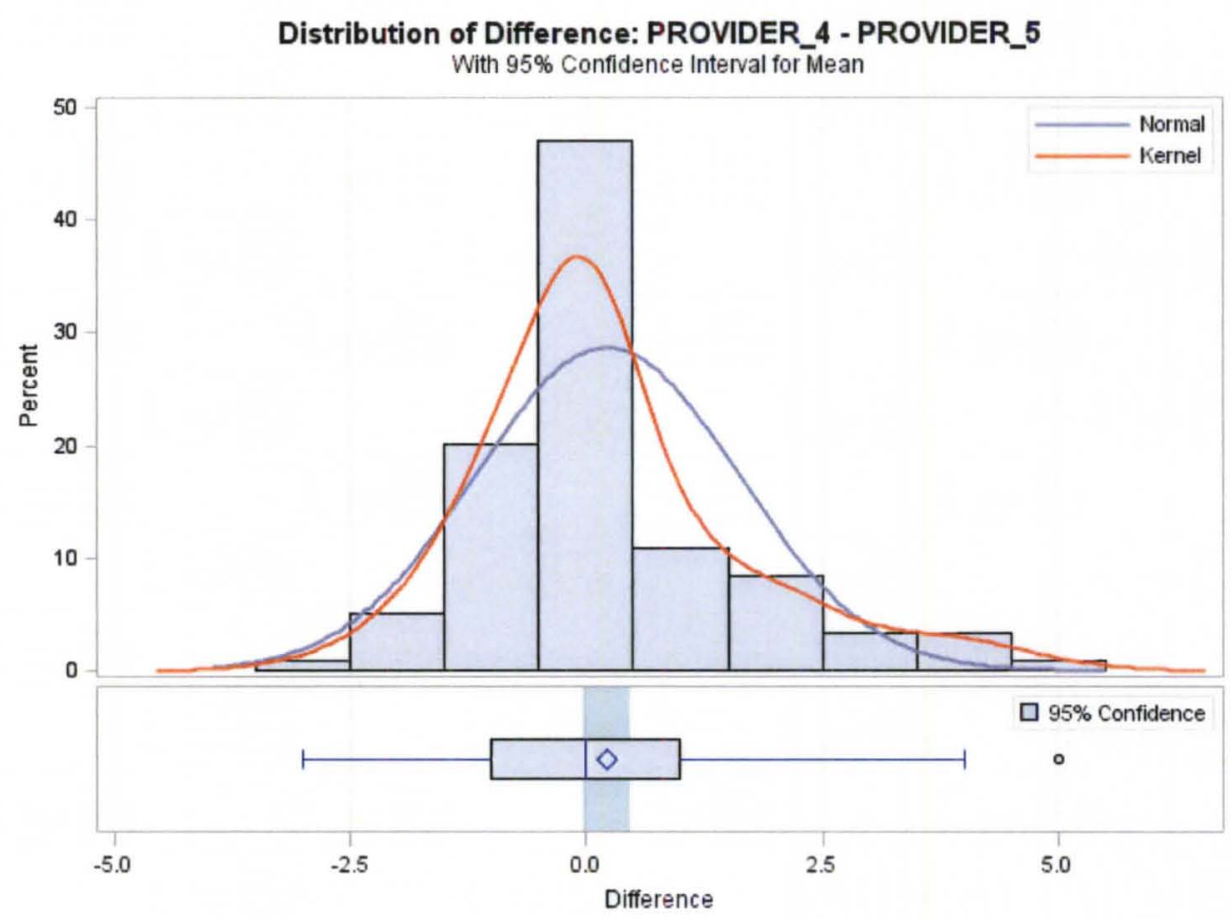

Table 4 provides agreement statistics for the different characteristics. The intraclass correlation coefficient is provided [22]. However there are some drawbacks to these, and therefore the Concordance Correlation Coefficient [2324] is also provided. Percent Agreement and Spearman's correlation coefficient are shown as well. The confidence intervals for Lin's concordance correlation coefficient are noticeably wide. This is because of the small sample size (4 subjects were included in the validity study, and some of these have missing values for some of the ratings).

Note that because of the exploratory nature of the study, no adjustments were made for multiple testing. 
Table 4: Agreement Statistics

\begin{tabular}{|c|c|c|c|c|c|c|}
\hline \multirow[b]{2}{*}{ Name } & \multirow[b]{2}{*}{$\operatorname{ICC}(2,1)$} & \multirow[b]{2}{*}{ Pct. Agr. } & \multirow[b]{2}{*}{ Spearman } & \multicolumn{3}{|c|}{ Concordance CC } \\
\hline & & & & $\mathrm{CCC}$ & $95 \%$ & \\
\hline Age & 1 & 1 & 1 & 1 & & \\
\hline Sex & & 1 & & & & \\
\hline GP_COL & 1 & 1 & 1 & 1 & & \\
\hline GP_Post & 0.800 & 0.750 & & 0.75 & 0.39 & 0.91 \\
\hline OR_COL & & 0.75 & & & & \\
\hline OR_Post & 0.654 & 0.25 & & 0.59 & -0.22 & 0.92 \\
\hline PROVIDER_2 & 0.691 & 0.33 & 0.330 & 0.50 & -0.49 & 0.93 \\
\hline PROVIDER_3 & 1 & 1 & 1 & & & \\
\hline PROVIDER_4 & 0.294 & 0.5 & - & & & \\
\hline PROVIDER_5 & 0.800 & 0.75 & 0.940 & 0.75 & 0.05 & 0.96 \\
\hline
\end{tabular}

Abbreviations: $\operatorname{ICC}(2,1)$-intraclass correlation coefficient used when all subjects are rated by the same raters who are assumed to be a random subset of all possible raters. Spearman-Spearman Correlation; CCC-Lin's Concordance Correlation Coefficient; Pct. Agr. - Percent Agreement; 95\% $\mathrm{Cl}$ - 95\% Confidence Intervals.

Figure 10

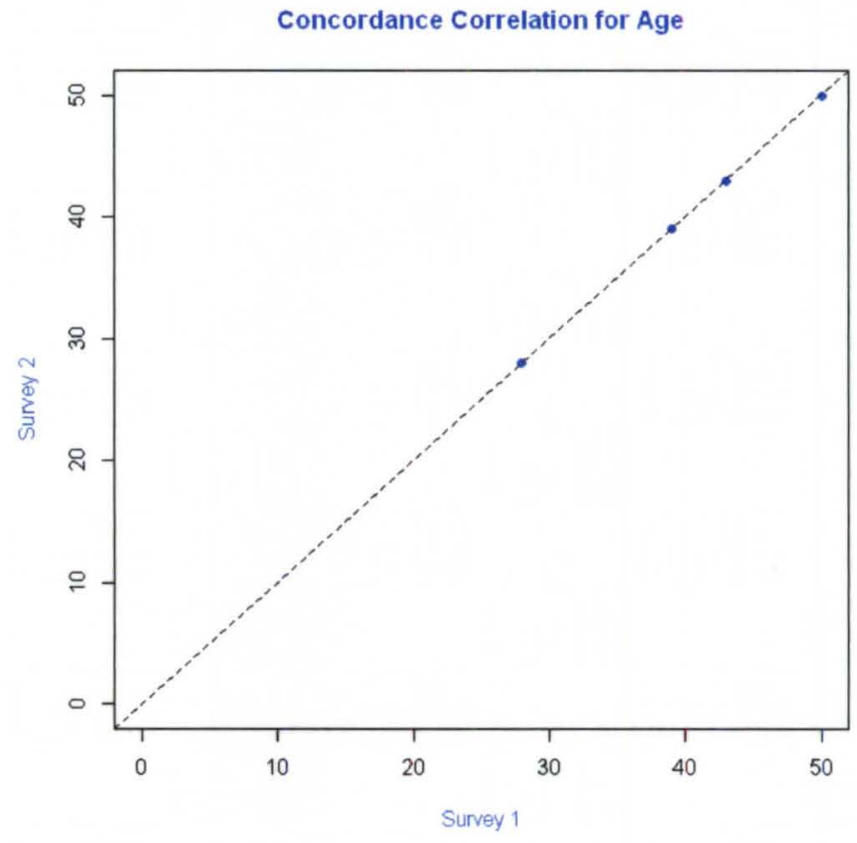


Figure 11

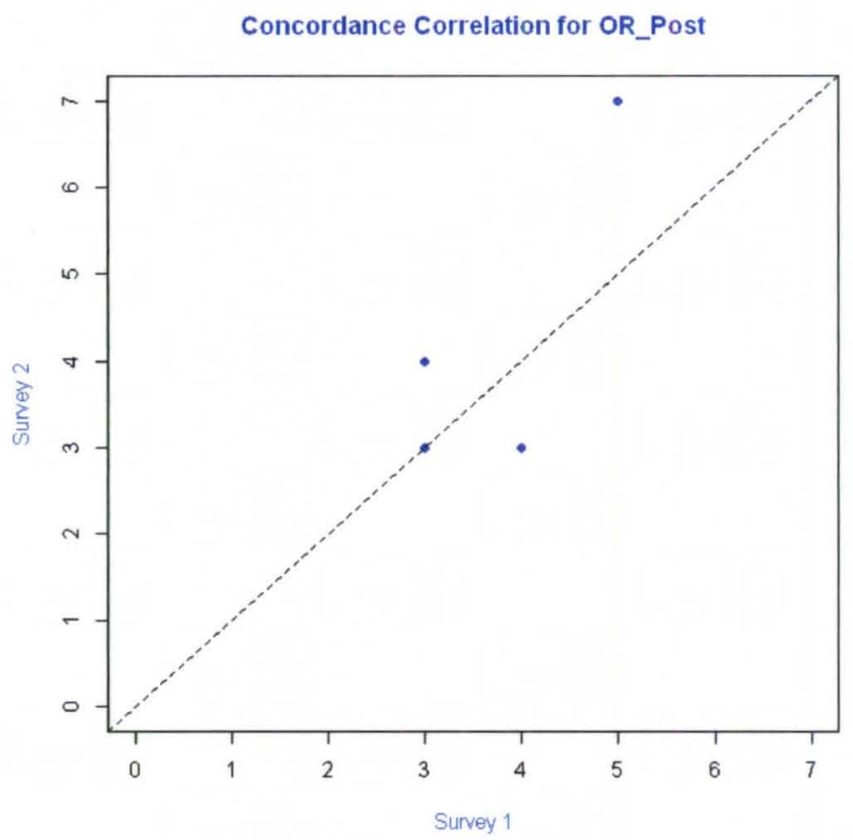

Figure 12

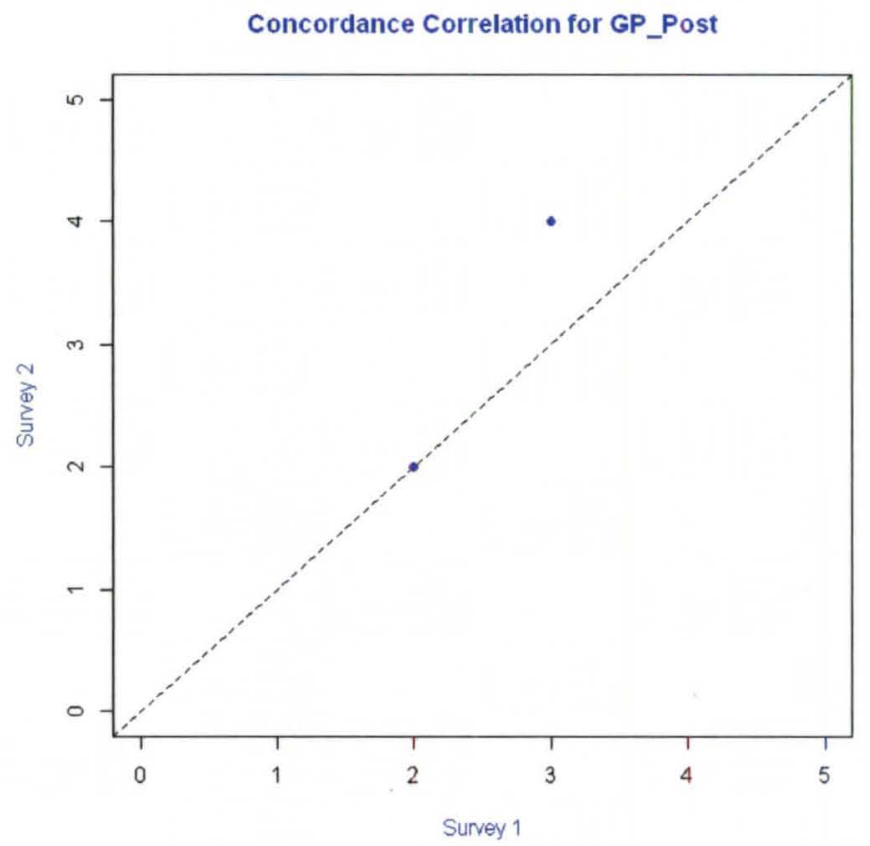


Figure 13

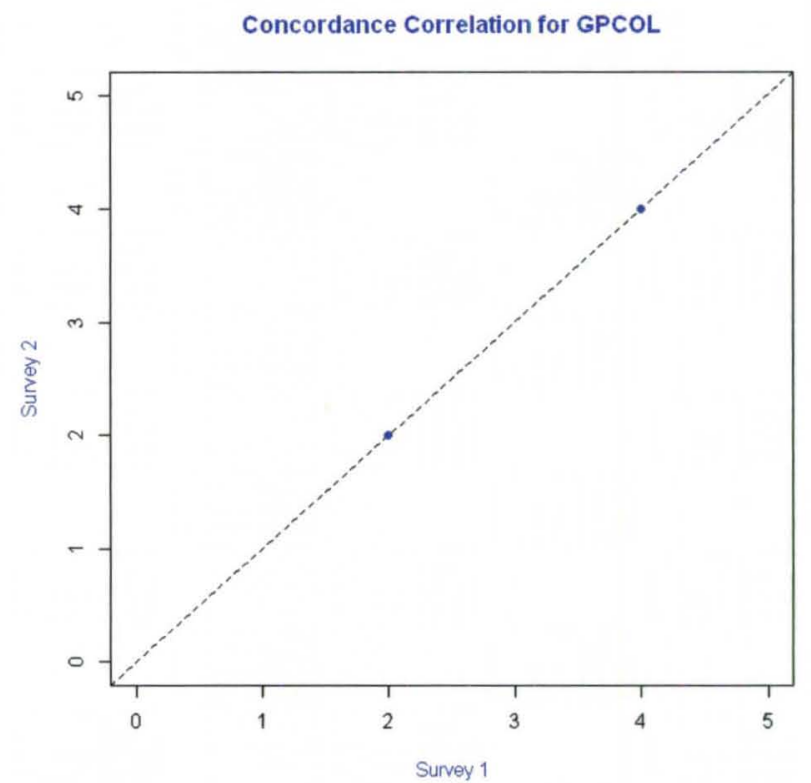

Figure 14

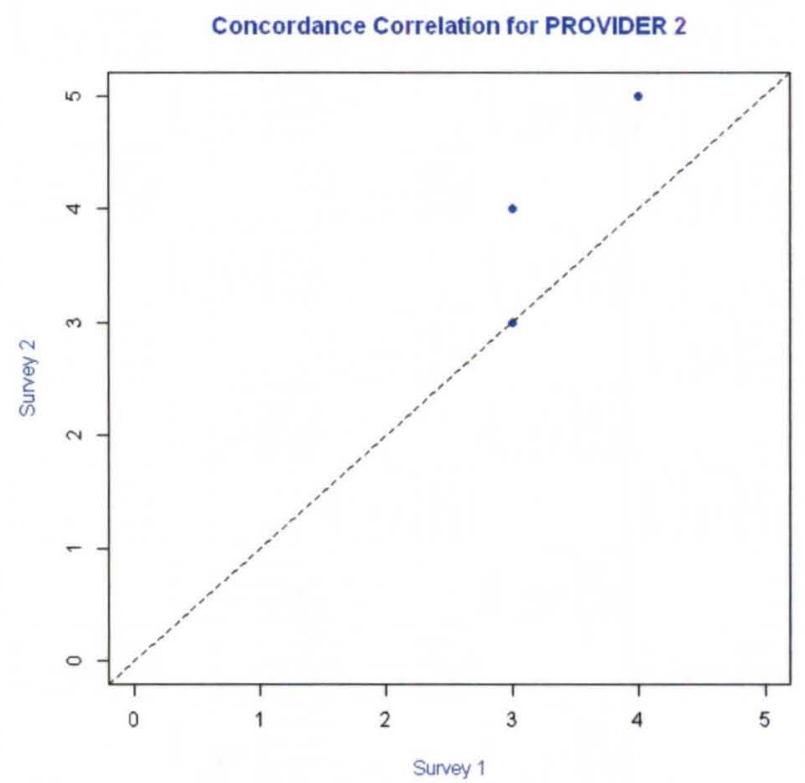


Figure 15

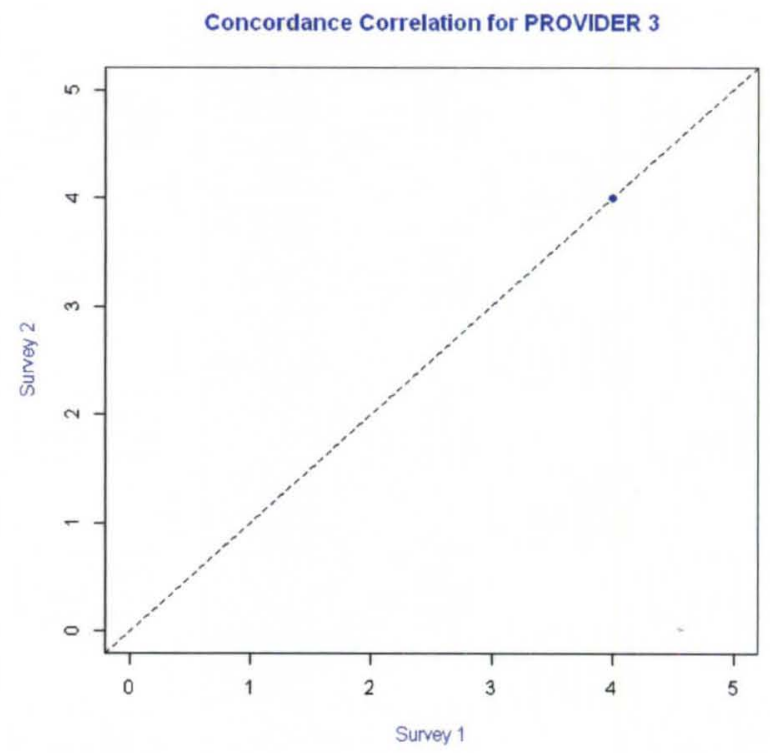

Figure 16

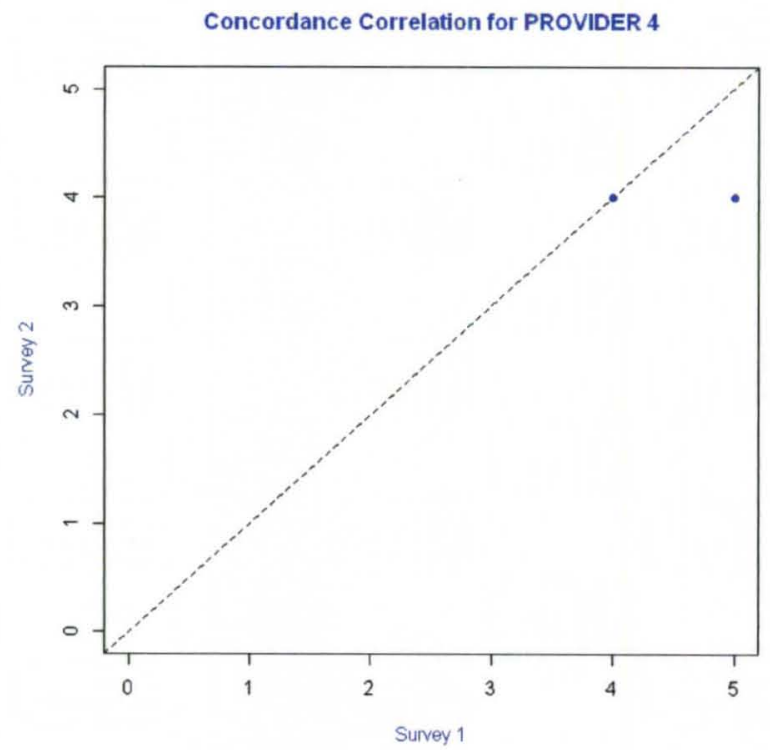


Figure 17

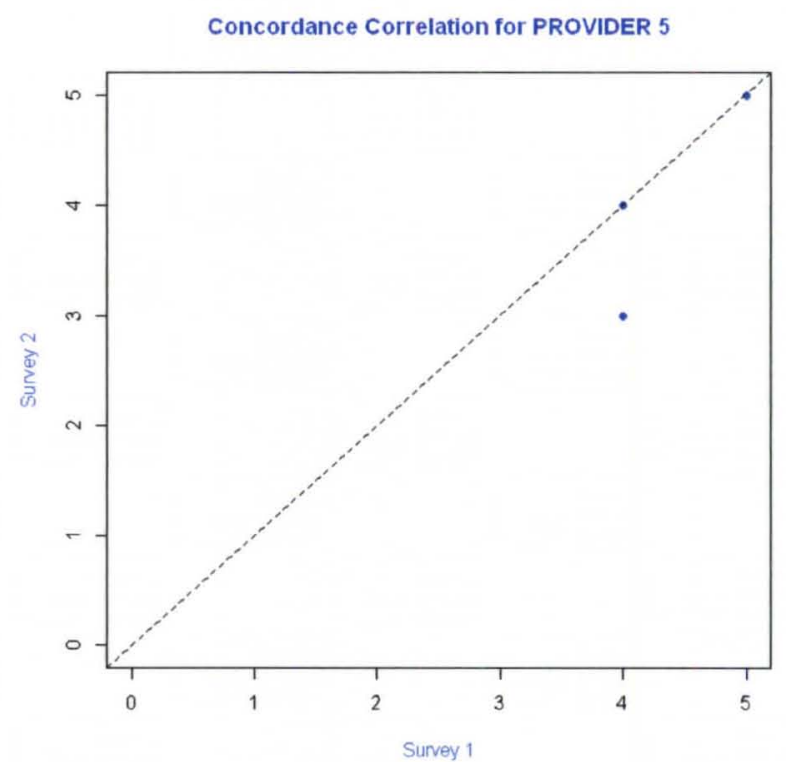




\section{CHAPTER IV}

\section{DISCUSSION}

Orthodontists today are faced with challenges that didn't exist 10 years ago. The days are gone when patients only seek orthodontists to correct their smile. Most patients are comfortable with their general dentist providing orthodontic treatment and some prefer it.[16] This survey had answers for why patients would choose provider \#5 such as: "Love the idea that family dentist could also be the family orthodontist. Much more personable and very much more convenient than going between the two" and "I would more than likely go with a family dentist for well rounded care."

Newly formed orthodontic residency programs are also flooding the work force with orthodontists faster than the population can keep up.[4] New orthodontists must compete for patients and even established practices must focus increasingly on marketing strategies to maintain new patients.

The surveyed population was primarily female at $78.4 \%$. This is consistent with other studies that have found that women are the primary decision makers when it comes to choosing an orthodontist.[15] The population was also primarily 3049 years old. This is the demographic that primarily has children aged 7-15 (the target age for orthodontists). 
The results showed accuracy in the total years of education for orthodontist at 8.67 (actually 10-11) and general dentist at 7.18 (actually 8 ) The results of the study also showed that the surveyed population does recognize the difference in education levels between orthodontists and general dentists as an extra 1.52 years. This number is slightly lower than $2-3$ years, but the age group that would most likely have children ages 7-15 (age orthodontist usually treat) was more accurate in their answers. Ages 30-39 answered 2.13 years and ages 40-49 answered 1.67 years. These are the age groups that the AAO have primarily focused on with their advertising campaign.[14]

This study also looked at how patients would recognize providers as authorities in the field by having a Master's degree and ABO certification. The Master's degree was not perceived by many perspective patients preferentially with patients only preferring provider \#2 to provider \#1 by 0.21 . Adding a Master's degree to the $\mathrm{ABO}$ certification (provider \#4) only increased preference by 0.38 when comparing provider \#3 to provider \#4. Some answers by those surveyed as to why they choose their selections for providers \#2 and \#4 were: "An MS can be in anything," "Not so much difference - only initials behind. DMD - Since I don't know what it stands for it doesn't really affect me," "What does MS mean. I would say that the more credentials the better but as a BSN I do not know what MS means. Unable to answer. Sorry."

The most preferred provider was the orthodontists with the most credentials, provider \#4 with a mean of 4.01. This was 1.01 higher than the orthodontists without any extra education/certifications, provider \#1. It was interesting that 
even though the overall mean was lower for provider \#5 (3.82), comparing provider \#5 to provider \#4 showed preference for provider \#5 by 0.22 . This difference however wasn't statistically significant. Provider \#5 was the general dentist providing orthodontics with certification through the National Board of Orthodontics. These results support the AAO's research that patients do not have a problem seeing their general dentist for their orthodontic treatment.

There was also no significant difference between provider \#3 (the orthodontist with $A B O$ certification) and provider \#5. Even though those surveyed perceived board certification preferentially, they didn't recognize the difference between an organization that certifies only orthodontic specialist and one that is for general dentists. This was expressed well by the participant that answered, "National board certified maybe as a teacher. National board sounds better to me than American Board, although they may be the same."

The results of the validity data were very weak. Ten surveys were planned to be passed out twice at the two consecutive appointments (about 4-6 week intervals). Only 4 of those initially surveyed where present to participate in the survey the second time. The patient either failed their appointment or a different parent brought the patient to the second appointment. Previous studies examining reliability by using the VAS reported a range of ICC values from 0.56 to 0.99 , and the most results from this study (ICC of .654-1.0) fell within the range reported in these previous studies.[26] Only provider \#4 had low ICC due to missing data for 2 of the surveys. The CCC for all the questions that were able to be tabulated also closely followed the line. 


\section{CHAPTER V \\ CONCLUSIONS}

\section{A. Summary:}

The aims of this paper were to determine if the patients or parents of patients at the University of Louisville orthodontic clinic were aware of the correct education levels for general dentists and orthodontists. The study also looked at if there was a perceived preference for an orthodontist with an increasing number of credentials/certifications or a general dentist with an orthodontic certification for providing orthodontic treatment. This study was able to determine that the surveyed population was accurate in their assessment of education levels for orthodontists and general dentists. The population had the strongest preference for the orthodontist with the most credentials, especially $A B O$ certification. A Master's degree was not understood by those surveyed very well and didn't exhibit much preference. This population would also likely see a general dentist for their orthodontic treatment needs.

\section{B. Conclusions:}

Possibly through the AAO's effort the sample population is aware of the difference in education levels between orthodontist and general dentists. Orthodontists that advertise their extra education/credentials may by preferentially viewed by prospective patients. $A B O$ certification may be a 
worthwhile pursuit to attract new patients. Advertising a Master's degree by itself may be viewed preferentially by patients. Orthodontics is at a crossroads and will have to compete directly with general dentist for future orthodontic patients. Orthodontics as a specialty must strive to educate the public about ways they are different than general dentists other than just of extra education.

This study had several weaknesses that could be corrected in future studies. There was only one population surveyed. Surveying a population of private practice patients or parent's of pediatric dentistry patients would allow for comparisons to the currently surveyed population. Many of the surveys weren't completely filled out. This could be corrected by using a computerized survey, more clear survey directions, someone checking surveys as they are handed in, or having a significantly increased number of surveys and being able to discard incomplete surveys.

There could have also been incorporated bias for the providers at the end of the survey. This could be corrected by randomizing the order of providers for the second question of the survey.

The validity data could have been more accurately collected. The number of surveys handed out twice was too low and the timeframe between surveys was too long. A larger group of participants could have been mailed another survey a week later or asked to go online and fill out an electronic survey a week after the first survey.

Future studies could correct these problems and look at other population groups. 


\section{REFERENCES}

1. http://www.aaomembers.org/Education/Accredited-Schools.cfm

2. Members' report. 2009-10 Survey of Dental Education Academic Programs, Enrollment, and Graduates - Volume 1. April 2011.

3. Board Report, New, Planned, and Proposed Schools of Dentistry Fall 2010 Report, VCU Dental School Board, 2010.

4. Howden L, Meyer J. Age and Sex Composition: 2010. US Census Briefs 2010. May 2011.

5. O'Neil J, Sheridan J. Positioning Your Practice in a Competitive Marketplace.

JCO, April 1995

6. Mindak W. Effective Marketing for Orthodontists. JCO, April 1987

7. Mayerson M. Management and Marketing. JCO, December 1996

8. Bates $v$ State Bar of Arizona, 433 US 350ZCOMMA384 (1977).

9. Becker BW, Kaldneberg DO. Avertising Expenditures by Professionals: an Exploratory Investigation of Dental Practitioners. J Advert. 1990; 19:23-27.

10. Keim RG, Gottieb EL, Nelson AH, Vogels DS. 2005 JCO Orthodontic Practice Study. Part 4: additional breakdowns. J Clin Orthod. 2005;40:95-102.

11. Edwards D, Shroff B, Lindauer S, Fowler C, Tufekci E. Media Advertising Effects on Consumer Perception of Orthodontic Treatment Quality. Angle Ortho 2008, 78:5.

12. Delaney N. The Benefits of Marketing in Orthodontics. British Journ of Ortho, November, 1998, 25:4 
13. Lingg B, Firestone A, Johnston W, Shanker S, Vig K. Prospective patients rate practice factors: Development of a questionnaire. AJODO, February 2010, 139:2.

14. Members' report. Research and Planning Group, American Association of Orthodontists. Consumer orthodontics study with patients and nonpatients., 1997.

15. Walley EK, Silberman SL, Tuncay OC. Patient and Partent Preferences for Orthodontic Practices. Clin Orthod Res 1999;2:110-123.

16. Members' report. Research and Planning Group, maerican Association of Orthodontists. Consumer orthodontics study with patients and nonpatients., 2006.

17. 2012 Consumer Awareness Program expands to Adult Patients. The Bulletin. 2012;30;2-9.

18. Cangialosi TH, Riolo MI, Owens S, Dykhouse VA, Moffitt AL, Grubb JO, Greco PE, English JE, James R. The ABO's $75^{\text {th }}$ Anniversayr: $A$ Retrospective Glance at Progress in the Last Quarter Century. AJODO. 204;125:279-83.

19. Riolo MI, Owens S, Dykhouse VA, Moffitt AL, Grubb JO, Greco PE, English JE, Briss BA, Cangialosi TH. A Change in the Certification Process by the American Board of Orthodontics. AM J Ortho Dentofacial Orthop 2005;127:278-81.

20. Harnick, DJ. Using clear aligner therapy to correct malocclusion with crowding and an open bite. Gen Dent. 2012;60(3):218-223

21. http://www.6monthsmiles.com

22. Shrout, P.E., and Fleiss, J.L (1979), "Intraclass Correlations: Uses In Assessing Rater Reliability," Psychological Bulletin, 86, 420-428.

23. Martin Bland J, Altman D: Statistical Methods For Assessing Agreement Between Two Methods Of Clinical Measurement. The Lancet 327:307310,1986 
24. Lin LIK: A Concordance Correlation Coefficient to Evaluate Reproducibility. Biometrics 45:255-268, 1989

25. Bijur PE, Silver W, Gallagher EJ. Reliability of the visual analog scale for measurement of acute pain. Acad Emerg Med 2001;8:1153-7. 


\section{CURRICULUM VITAE}

Name: Justin Trisler

Address: 228 Fairmeade $\mathrm{Rd}$

Louisville, KY 40207

justin.trisler@gmail.com

DOB: $\quad$ Clearwater, Florida - May 12, 1980

Education: University of Louisville Orthodontic Residency, July 2010-present

US Army 12-month AGD residency, July 2007

UAB School of Dentistry, D.M.D., June 2006

Berry College, B.S. May 2002

University of Georgia, August 1998 to December 2000

Honors and

Awards: $\quad$ Presidential Scholar Award, University of Georgia, September 1999

Martha Berry Work Service Award, March 2002

Alpha Chi National College Honor Scholarship Society, March 2000 Graduated Magna Cum Laude, Berry College

United States Army Health Professional Scholarship Award, August 2002 to present

The Army Achievement Medal, August 2006 to July 2007

\section{Professional Society Memberships:}

American Student Dental Association, 2002 to 2006

Academy of General Dentistry, 2006-2007

American Dental Association, 2006 to present

American Association of Orthodontists, 2010 to present

\section{Employment Experience:}

Army Captain, June 2006 to present

Oral Diagnosis Employee, summer and Christmas Holiday 2005

Army AGD 12-month program, August 2006 to July 2007 